\title{
TEXTURE, PLASTIC ANISOTROPY AND EARING BEHAVIOR IN $1.5 \%$ Si STEEL SHEETS
}

\author{
B.H.HAHN ${ }^{*}$, S.H.KIM* and Y.B.PARK** \\ - Department of Metallurgical Engineering, Seoul National University, \\ $151-742$, Seoul, Korea \\ Department of Material Engineering, Suncheon National University, \\ 540-070, Suncheon, Korea
}

\begin{abstract}
Texture, plastic anisotropy and earing behavior of $1.5 \% \mathrm{Si}$ steels which have high strength and good elongation were studied. In the case of slow heating to intercritical temperature, (222) plane slowly increased by selective grain growth of retained ferrite to the temperature which occured the grain growth of recystallized ferrite. But in rapid heating selective grain growth of retained ferrite did not occured because grain growth of recrystallized ferrite was interfered by austenite. And in slow heating and slow cooling, transformation also occured by selective grain growth of retained ferrite. The effect of second phase on plastic strain ratio in multi-phase steel was calculated using Eshelby's tensor. As the difference of plastic strain ratio between matrix and second phase and the volume fraction of second phase increased, R-value of multi-phase steel decreased. On the contrary if the second phase was elongated to the thickness direction and the difference of plastic strain ratio between matrix and second phase was small, the plastic strain ratio of multiphase steel increased. Earing appeared at $45^{\circ}$ direction in $\mathrm{Cu}$ added steel, but earing appeared at $0^{\circ}, 90^{\circ}$ in $\mathrm{Cu}$ not added steel.
\end{abstract}

INTRODUCTION

$1.5 \% \mathrm{Si}$ steels were developed in sheet having high strength and good formability. The microconstituents were ferrite and second phase. The second phases were pearlite or bainite, retained austenite and martensite according to the cooling rate. When low carbon steel was annealed at intercritical temperature region, there were report that there is a special temperature at which maximum value of (222) pole intensity was appeared. ${ }^{1-4}$ ) A main factor which has an effect on the $\mathrm{R}$-value is texture. In ferrite single phase steel, (222) texture component parallel to rolling plane was favourable to the $R$-value. But in multiphase steel the R-value was influenced by the second phase. $\left.{ }^{5,6}\right)$

In present study, change of texture of untransformed ferrite was measured using high temperature $\mathrm{X}$-ray diffractometer at intercritical region. And the internal strength produced by the existence of second phase was calculated using Eshelby's tensor. 


\section{EXPERIMENT}

The chemical composition of the steels used in this study was given in Table 1 . The specimens were cold rolled up to $75 \%$ rolling reduction. Final thickness of all specimens was $0.75 \mathrm{~mm}$. After cold rolling, the specimens were annealed at intercritical temperature. Here the variants were heating rate, holding time and cooling rate. And inverse pole figure was measured with high temperature X-ray diffractometer. Rvalue of multi-phase steel was measured by tensile test. The internal strength produced by inhomogeneous deformation between matrix and second phase in tensile test of multi-phase steel was calculated using Eshelby's tensor. And R-value was calculated using Bunge and Lee-Oh method from ODF data. Earing behavior was also studied using Erichen tester.

Table.1 Chemical composition of specimens ( in wt.\%)

\begin{tabular}{|c|c|c|c|c|c|c|c|c|c|}
\hline Stecl & $\mathrm{C}$ & $\mathrm{Si}$ & $\mathrm{Mn}$ & $\mathrm{P}$ & $\mathrm{S}$ & $\mathrm{Cr}$ & $\mathrm{Cu}$ & $\mathrm{Ti}$ & $\mathrm{Al}$ \\
\hline S1 & .12 & 1.56 & .49 & .016 & .010 & .52 & .78 & .019 & .07 \\
\hline S2 & .156 & 1.53 & .52 & .020 & .012 & .52 & .87 & .018 & .045 \\
\hline S3 & .193 & 1.49 & .51 & .015 & $.0(17$ & .49 & .75 & .017 & .085 \\
\hline S4 & .102 & 1.47 & .47 & .014 & .007 & .52 & - & .02 & .075 \\
\hline
\end{tabular}

\section{RESULTS AND DISCUSSION}

The microstructure of specimens after annealing at intercritical region was shown in photo 1 . The final microconstituents were ferrite, bainite, retained austenite and martensite in the case of isothermal transformation after rapid heating. And the microconstituents were ferrite and pearlite after slow heating and furnace cooling. As has been shown in photo 1 (a), (c) the second phase was near to the sphere, but the second phase which was shown in photo 1 (b) was elongated to the rolling direction.

Table 2 shows the results of high temperature $\mathrm{X}$-ray diffractometer test. (222), (211) texture in retained ferrite have been developed at intercritical region. In the case of slow heating to intercritical temperature (222) plane slowly increased by selective grain growth of retained ferrite to the temperature $\left(860^{\circ} \mathrm{C}\right)$ which occured the grain growth of retained ferrite. That is, in slow heating ferrite-austenite transformation occured after recrystallization of ferrite. So the specimen was heated to the intercritical region in the state that (222) texture have been developed, therefore in slow heating selective grain growth of retained ferrite occured, and in slow cooling transformation also occured by selective grain growth of retained ferrite. On the contrary in rapid heating, recrystallization of ferrite and transformation of ferrite to austenite occured at the same time, so growth of recrystallized ferrite was interfered by austenite. Therefore in rapid heating, selective grain growth of retained ferrite did not occured, and transformation by selective grain growth of retained ferrite did not occured in cooling.

Tomota $^{8)}$ etc have induced the internal strength produced by deformation difference between matrix and second phase using Eshelby's tensor. Here we modified the Tomota's theory, that is, we introduced the concept of deformation anisotropy. So we assumed that plastic strain ratio of matrix is unit, and that of second phase is $R_{1}$ which is smaller than unit. In above case tensile stress was produced in matrix and 
Tablc.2 Texture coefficient of
reflection planes in S1 stecl

(a) Variation of T.C at high tcmp.

\begin{tabular}{|l|l|l|l|l|l|}
\hline $\mathrm{cmp}$ & $(222)$ & $(310)$ & $(211)$ & $(200)$ & $(110)$ \\
\hline 730 & 3.05 & 0.16 & 1.48 & 0.3 & 0.01 \\
\hline 760 & 3.06 & 0.02 & 1.39 & 0.51 & 0.02 \\
\hline 790 & 3.09 & 0.02 & 1.45 & 0.43 & 0.01 \\
\hline 830 & 3.21 & 0.01 & 1.42 & 0.35 & 0.01 \\
\hline 860 & 3.25 & 0.01 & 1.62 & 0.12 & 0.00 \\
\hline 880 & 2.85 & 0.01 & 1.67 & 0.46 & 0.01 \\
\hline 910 & 2.84 & 0.02 & 1.68 & 0.47 & 0.00 \\
\hline 950 & 2.76 & 0.02 & 1.82 & 0.41 & 0.00 \\
\hline
\end{tabular}

(b) Variation of T.C with heating rate at $830^{\circ} \mathrm{C}$

\begin{tabular}{|l|c|c|c|c|c|}
\hline & $(222)$ & $(310)$ & $(211)$ & $(200)$ & $(110)$ \\
\hline S.H & 3.21 & 0.01 & 1.42 & 0.35 & 0.01 \\
\hline R.H & 2.79 & 0.04 & 1.35 & 0.76 & 0.06 \\
\hline
\end{tabular}

(c) Variation of T.C at room temp. (annealed at $830^{\circ} \mathrm{C}$ )

\begin{tabular}{|l|c|c|c|c|c|}
\hline & $(222)$ & $(310)$ & $(211)$ & $(200)$ & $(110)$ \\
\hline S.H-S.C & 3.57 & 0.03 & 1.17 & 0.22 & 0.01 \\
\hline S.H-I.C & 3.36 & 0.08 & 1.16 & 0.36 & 0.04 \\
\hline S.H-R.C & 3.22 & 0.09 & 1.30 & 0.38 & 0.03 \\
\hline R.H-S.C & 3.16 & 0.18 & 1.13 & 0.47 & 0.06 \\
\hline R.H-R.C & 3.16 & 0.13 & 1.24 & 0.44 & 0.03 \\
\hline
\end{tabular}

S.H : slow hcating $\left(200^{\circ} \mathrm{C} / \mathrm{hr}\right)$

S.C : slow cooling $\left(100^{\circ} \mathrm{C} / \mathrm{hr}\right)$

R.H : rapid hcating $\left(100^{\circ} \mathrm{C} / \mathrm{min}\right)$

R.C : rapid cooling $\left(210^{\circ} \mathrm{C} / \mathrm{min}\right)$

I.C : intermediate cooling $\left(50^{\circ} \mathrm{C} / \mathrm{hr}\right)$

compressive stress was produced in second phase at width and thickness direction in tensile deformation.

Fig.12 show the internal strength difference produced by existance of second phase in tensile deformation. Here the internal strength difference means to subtract the internal strength in the thickness direction from that in the width direction. In Fig.1, true strain of matrix is 0.14 and true strain of second phase is 0.1 . Regardless of the shape of second phase, as the difference of plastic strain ratio between matrix and second phase decreased the internal strength difference decreased. The second phase was more elongated to the width direction than the thickness direction in deformation, so deformation in the width direction was more interfered than in the thickness direction, therefore the plastic strain ratio of multi-phase steel reduced. On the contrary if the second phase was elongated to the thickness direction and the difference of plastic strain ratio between matrix and second phase was small, the internal strength in the thickness direction was greater than in the width direction so plastic strain ratio of multi-phase steel increased. As shown in Fig.2, if the dimension of second phase in the width and the thickness direction was same and second phase did not strain, the plastic strain ratio of multi-phase steel was not influenced by second phase. And if the second phase was prolate type or spherical type, the internal strength difference increased with the deformation of second phase. If the second phase was deformed, the deformation difference between matrix and second phase reduced. So the internal strength difference also reduced. But the second phase was more deformed in the thickness direction, because $\mathbf{R}$-value of second phase is lower than unit. Therefore the reduce of internal strength in the thickness direction was larger than that in the width direction.

Fig. 3,4 show the variation of measured and calculated R-value. In rapid heating and isothermal transformation (Fig.3), as the intercritical temperature raised, that is, volume fration of second phase increased, the deviation between measured and calculated value was increased. It was thought that because the internal strength difference increased with the volume fraction of second phase. As shown in Fig.4(a) the tendency of variation of $R$-value at $0^{\circ}, 45^{\circ}$ direction was same in measured and 
calculated case, but the deviation was larger at $90^{\circ}$ direction than other direction. As have been shown in Photo 1(b) the second phase was elongated to the rolling direction. When the specimen was deformed at $90^{\circ}$ direction, the shape of second phase was elongated to the width direction. So measured $\mathrm{R}$-value at $90^{\circ}$ direction decreased by not only second phase shape but also second phase itself. And in Fig.4(b) the tendency of variation of measured and calculated value was same. Because the shape of second phase was near to the sphere, decrease of $R$-value at special direction did not occured.

Earing appeared at $45^{\circ}$ direction in $\mathrm{Cu}$ added steel, but earing appeared at $0^{\circ}, 90^{\circ}$ in $\mathrm{Cu}$ not added steel.

\section{CONCLUSION}

In the case of slow heating to intercritical temperature, (222) plane slowly increased by selective grain growth of retained ferrite to the temperature which occured the grain growth of recystallized ferrite. And in slow heating and slow cooling, transformation also occured by selective grain growth of retained ferrite. As the difference of plastic strain ratio between matrix and second phase and the volume fraction of second phase increased, R-value of multi-phase steel decreased. On the contrary if the second phase was elongated to the thickness direction and the difference of plastic strain ratio between matrix and second phase was small, the plastic strain ratio of multi-phase steel increased. Earing appeared at $45^{\circ}$ direction in $\mathrm{Cu}$ added steel, but earing appeared at $0^{\circ}$, $90^{\circ}$ in $\mathrm{Cu}$ not added steel.

\section{REFERENCE}

1. R.M.S.B. Horta, D.V. Wilson and W.T. Roberts , JISI, 210, 42 (1972)

2. K. Saiki , J. Jpn. Soc. Technol. Plast., 9, 108 (1968)

3. O. Hashimoto, S. Satoh and T. Tanaka, Trans. ISIJ, 27, 746 (1987)

4. O. Hashimoto, S. Satoh and T. Tanaka , Trans. ISIJ, 23, 1028 (1983)

5. K. Kurihara, Y. Hosoya and K. Nakaoka , Proceedings of 6th International Conference on Texture of Materials ed. by Nagashima (Tokyo, 1981) p.1066

6. M. Sudo, I. Tsukatani and Z Shibata, Metallurgy of Continuous Annealed Sheet Steel ed. by B.L Bramfitt etc (Dallas, 1982) p.301

7. J.D. Eshelby , Proc. Roy. Soc., A241, 376 (1957)

8. Y. Tomota, K. Kuroki, T. Mori and I. Tamura , Mat. Sci. Eng., 24, 85 (1976) 


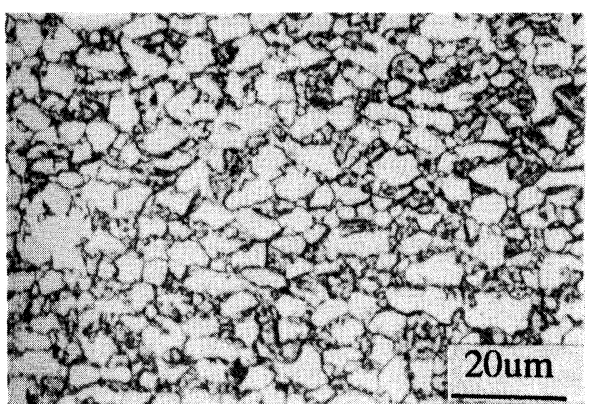

(a)

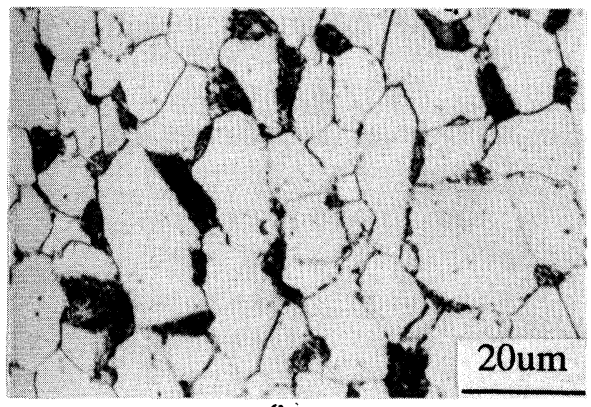

(b)

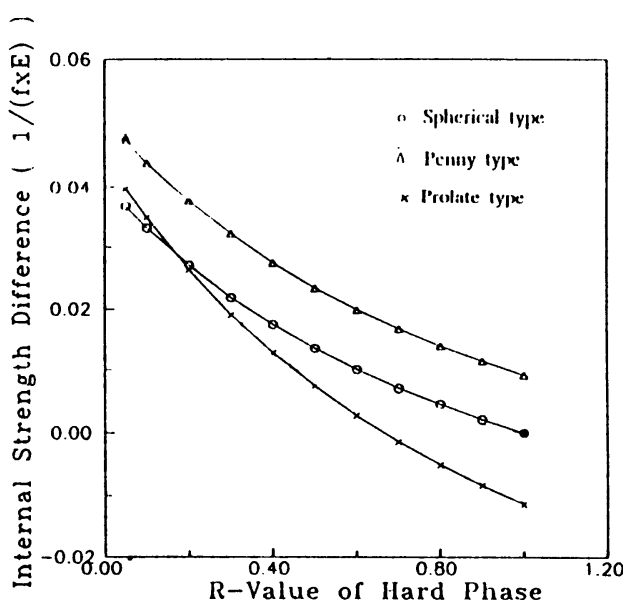

Fig.1 Internal stress difference between width and thickness direction with $\bar{R}$ value of hard phase ( $\mathrm{f}$; hard phase volume fraction, E; clastic constant of soft phasc )

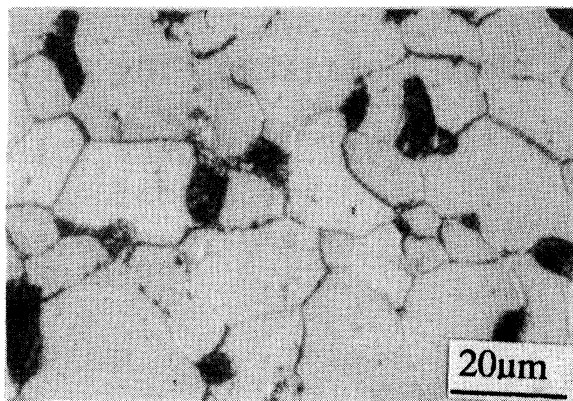

(c)

Photo.1 Optical micrographs of S1 steel (a) annealed at $880^{\circ} \mathrm{C}$, rapid heating and isothermal transformation (b) anncaled at $790^{\circ} \mathrm{C}$, slow heating and slow cooling (c) annealed at $950^{\circ} \mathrm{C}$, slow heating and slow cooling

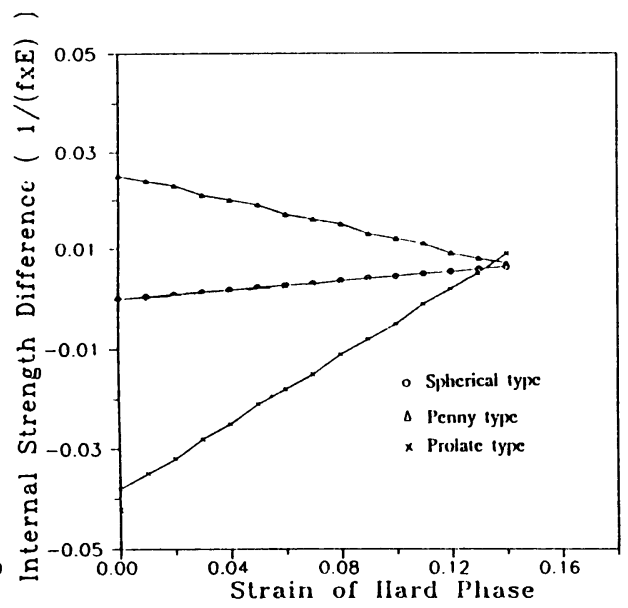

Fig.2 Internal stress difference between width and thickness direction with strain of hard phase ( $\bar{R}$ value of hard phase ; 0.8 ) 


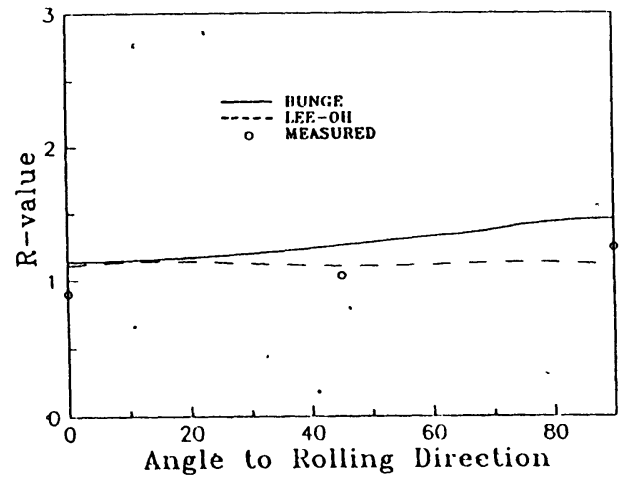

(a)

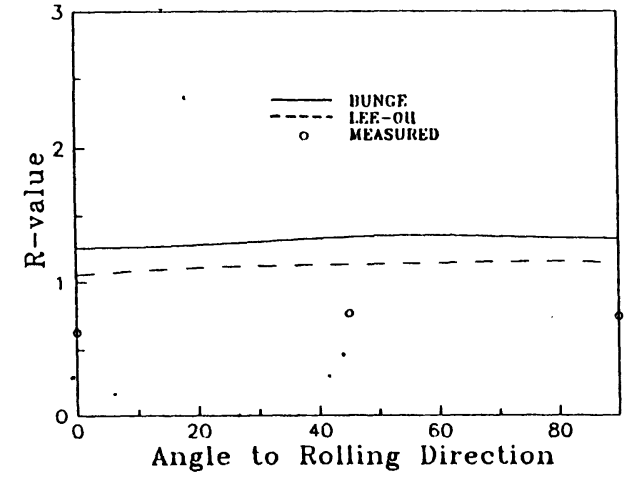

(b)

Fig.3 Plastic strain ratio as a function of angle to rolling direction for S1 stecl annealed at (rapid heating,isothermal transformation) (a) $760^{\circ} \mathrm{C}$ (b) $970^{\circ} \mathrm{C}$

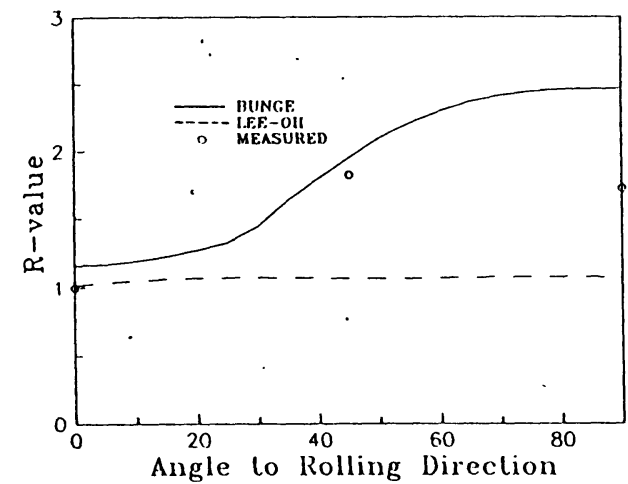

(a)

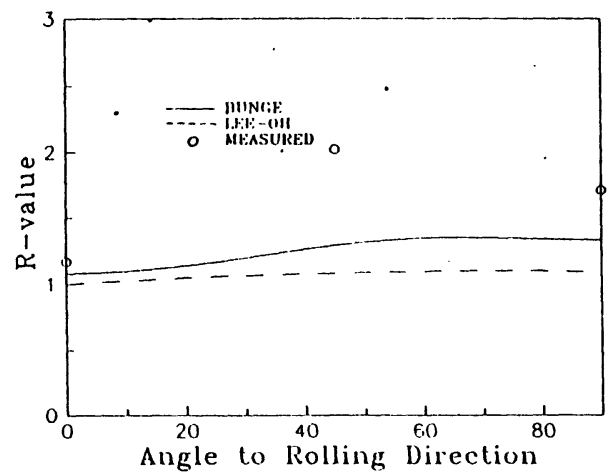

(b)

Fig.4 Plastic strain ratio as a function of angle to rolling direction for S1 steel annealed at (slow heating, slow cooling) (a) $790^{\circ} \mathrm{C}$ (b) $950^{\circ} \mathrm{C}$

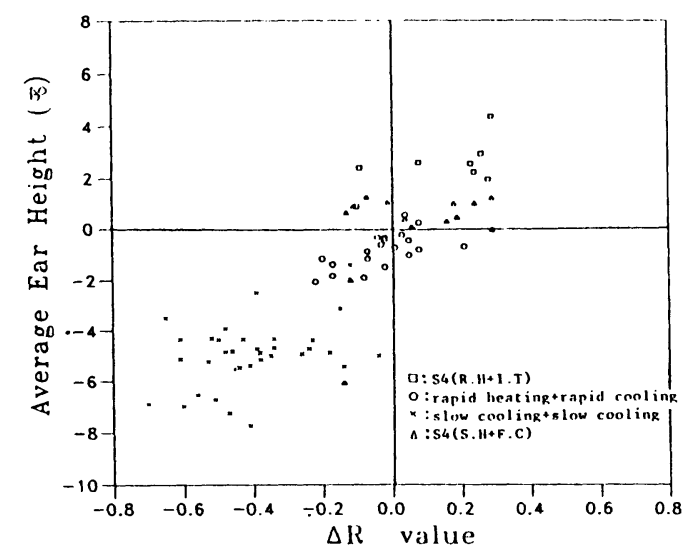

Fig.5 Relation between $\Delta \mathrm{R}$ value and average ear height 